\begin{tabular}{c} 
I(I) International Journal of Chemistry and Technology \\
$\frac{\mathrm{http} / / \text { dergipark.org.tr/ijct }}{\text { Research Article }}$ \\
\hline
\end{tabular}

\title{
Synthesis and characterization of a new 2D-imine-linked covalent organic framework
}

\author{
Lalehan AKYÜZ \\ Department of Chemistry Technology, Technical Vocational School, Aksaray University, Aksaray 68100, Turkey
}

Received: 10 July 2020; Revised: 21 August 2020; Accepted: 11 September 2020

*Corresponding author e-mail: lale_akyuz@hotmail.com

Citation: Akyüz, L. Int. J. Chem. Technol. 2020, 4 (2), 171-178.

\begin{abstract}
Covalent organic structures (COFs) are extraordinarily porous solids defined as organic polymeric materials with large surface area. COF compounds are widely studied for nanotechnology applications. Additionally, there are applications for its usability in semiconductor technologies and drug delivery systems. Within the scope of this article, a new covalent organic structure $(\mathrm{COF})$ was synthesized using triformylbenzene (TFB) and 3,3',5,5'-tetramethyl benzidine (TMB), which were not previously included in the literature. The compound synthesized here is the two-dimensional iminelinked COF (LA-COF-2) compound. The synthesized COF compound was characterized using FT-IR, SEM, TGA, PXRD and elemental analysis. The LA-COF- 2 compound is composed of aggregated particles of approximately $200 \mathrm{~nm}$. The thermal stability of LA-COF-2 compound is high and compatible with the literature. The compound is stable to base, $\mathrm{N}, \mathrm{N}-$ Dimethylacetamide (DMA) and water.
\end{abstract}

Keywords: Synthesis, characterization, covalent organic framework (COF).

\section{Yeni bir 2D-imin bağlı kovalent organik yapının sentezi ve karakterizasyonu}

ÖZ

Kovalent organik yapılar (COFs), geniş yüzey alanına sahip organik polimerik malzemeler olarak tanımlanan olağanüstü gözenekli katı maddelerdir. COF bileşikleri nanoteknoloji uygulamaları için geniş çapta incelenmektedir. Ek olarak, yarı iletken teknolojilerinde ve ilaç dağıtım sistemlerinde kullanılabilirliği için uygulamalar vardır. Bu proje kapsamında triformilbenzen (TFB) ve 3,3',5,5'-tetrametil benzidin (TMB) kullanılarak, daha önce literatürde yer almayan yeni bir kovalent organik kafes (covalent organic framework-COF) yapısı sentezlenmiştir. Burada sentezlenen bileşik, iki boyutlu imine bağlı COF (LA-COF-2) bileşiğidir. Sentezlenen COF bileşiği FT-IR, SEM, TGA, PXRD ve elementel analiz kullanılarak karakterize edildi. LA-COF-2 bileşiği, yaklaşık 200 nm'lik kümelenmiş partiküllerden oluşmaktadır. LA-COF-2 bileşiğinin termal kararlılığı yüksektir ve literatür ile uyumludur. Bileşik baz, N,N-dimetilasetamit (DMA) ve suya karşı karalıdır.

Anahtar Kelimeler:Sentez, karakterizasyon, kovalent organic kafes (COF).

different structures have been synthesized using monomers with different functional groups. ${ }^{3-8}$ Especially, due to the COFs derived from B-O bonds with low chemical stability, COFs containing $\mathrm{C}-\mathrm{N}$ bonds such as imine, ${ }^{6,9-11}$ triazine $^{12}$ and hydrazon ${ }^{13}$ linkages have also been improved in addition to boron compounds, over times. In particular, two-dimensional crystalline COFs have attracted attention as porous crystalline polymers. 2D-COFs have been investigated for nanotechnology application areas such as conductivity, ${ }^{14,15}$ optoelectron devices, ${ }^{16}$ optical sensing, ${ }^{3,7,17}$ catalizing ${ }^{18}$ and electrochemical sensing ${ }^{19}$ due to their electron rich, big $\pi$-delocalization and film forming properties. 
Schiff base condensation reactions are widely used for the preparation of COFs via solvothermal reactions in sealed vials. ${ }^{1}$ Herein, a new framework-based imine linked COF material has been designed and synthesized with the condensation reaction of building block 3,3',5,5'-tetramethyl benzidine (TMB) with linking unit triformylbenzene (TFB). The COF synthesis reaction was performed in under solvothermal conditions. The characterization of COF was investigated using FT-IR, SEM, TGA, PXRD and elemental analysis. In addition, the chemical stability of COF was investigated in base (6 $\mathrm{N} \mathrm{NaOH}$ ), N,N-Dimethylacetamide (DMA) and water by using TGA and FT-IR analyses.

\section{MATERIALS AND METHODS}

\subsection{Chemical and reagents}

TFB and TMB were obtained from Sigma Aldrich. mesitylene, 1,4-dioxane, ethanol, dimethylformamide and tetrahydro furan were purchased from Merck. All other reagents were of analytical grade.

\subsection{FT-IR analysis}

FT-IR spectra were obtained using a Perkin Elmer mark FT-IR Spectrophotometer. The spectra were recorded for starting materials and LA-COF-2 at the scanning range of 4,000-650 $\mathrm{cm}^{-1}$.

\subsection{Thermogravimetric analysis}

The thermogravimetric analysis (TGA) was carried out on NETSZCH TGA-DSC Thermogravimetric Analyzer. The analyses were done under $\mathrm{N}_{2}$ gas flow, and the samples were heated from $0^{\circ} \mathrm{C}$ to $700^{\circ} \mathrm{C}$ at $10 \mathrm{~K} / \mathrm{min}$.

\subsection{Powder X-ray diffraction}

Powder X-ray diffraction (PXRD) analyses were carried out using a full-fledged Bruker D8 Advance instrument with $\mathrm{Cu} \mathrm{K \alpha}$ line focused radiation at $40 \mathrm{kV}$ and $40 \mathrm{~mA}$ from $2 \theta=3.0^{\circ}$ up to $90^{\circ}$.

\subsection{Field emission-scanning electron microscopy (FE-SEM)}

Scanning electron microscopy (SEM) was carried out using a LEICA/CAMBRIDGE LEO S-440 STEREOSCAN SEM to investigate the surface morphology of the samples. The materials were coated with gold as a thin layer using a Gatan Precision Etching Coating System (PECS).

\subsection{Synthesis of LA-COF-2}

TMB (32.979 mg, 0.155 mmole), TFB (14.595 mg, 0.09 mmole), $3 \mathrm{ml}$ 1,4-dioxane and $0.6 \mathrm{ml} 3 \mathrm{M}$ acetic acid were poured into the pyrex tube. The pyrex tube was frozen with liquid $\mathrm{N}_{2}$ and evacuated the 150 mTorr internal pressure. The evacuated pyrex tube was placed at $180^{\circ} \mathrm{C}$ in an oven and reaction was continued for 3 days to yield a yellow solid in pyrex tube. The precipitate was obtained by filtration and washed three times with $10 \mathrm{ml}$ of anhydrous THF and DMA and acetone. The solid which is insoluble in common organic solvents was dried at $100^{\circ} \mathrm{C}$ for $12 \mathrm{~h}$. Yield: $76 \%$. Elemental analysis, calculated; $\left(\mathrm{C}_{144} \mathrm{H}_{126} \mathrm{~N}_{12}\right)_{\mathrm{n}}$ : C 85.46; H 6.23; N 8.31. Found; C 84.01; H 6.91; N 8.82; O 0.26 .

\subsection{Chemical stability}

The chemical stability of LA-COF-2 was investigated in $6 \mathrm{~N} \mathrm{NaOH}$, distilled water and DMA. Correctly weighed LA-COF-2 samples were placed in $20 \mathrm{ml}$ of $6 \mathrm{~N} \mathrm{NaOH}, \mathrm{DMA}$ and distilled water and carefully mixed for $120 \mathrm{~h}$. The mixtures were filtered by the centrifuge. The precipitate was dried at $100^{\circ} \mathrm{C}$ for $24 \mathrm{~h}$. The dried samples were weighed again, and mass losses were determined. FT-IR analyses were repeated for the treated samples. Spectra were compared to the starting spectrum of LA-COF-2 samples. In addition, TGA thermograms were compared to determine the change in the thermal stability of the samples treated.

\section{RESULTS AND DISCUSSION}

LA-COF-2 shown in Figure 1a was synthesized by heating the suspension of 3,3'-dimethoxybiphenyl-4,4'diamine and TFB in a mixture of 1,4-dioxane and aqueous acetic acid within the sealed pyrex tube. LACOF-2 is insoluble in common organic solvents such as dimethyl sulfoxide, tetrahydrofuran, acetone, N,Ndimethylformamide. The honeycomb structure of LACOF-2 is given in the Figure $1 \mathrm{~b}$.

\subsection{FT-IR analysis}

FT-IR analyses were performed to confirm the imine linkages formed between aldehyde and primary amine functional group of the starting material. The spectra of LA-COF-2, TMB and TFB compounds are given in Figure 2a. FT-IR spectrum of LA-COF-2 showed that the imine linkage peak $(\mathrm{C}=\mathrm{N}$ stretching) was observed at $1626 \mathrm{~cm}^{-1}$. When compared the spectra of starting materials with the LA-COF-2, the $\mathrm{C}=\mathrm{O}$ and $\mathrm{N}-\mathrm{H}$ bands of starting materials are weaker in LA-COF-2. The attenuation of the peaks is further evidence of the formation of the imine linkages. Also, it can be concluded that the weak peaks at these wave numbers were attributed to the unreacted terminal amino and aldehyde groups of $\mathrm{COF}$. 


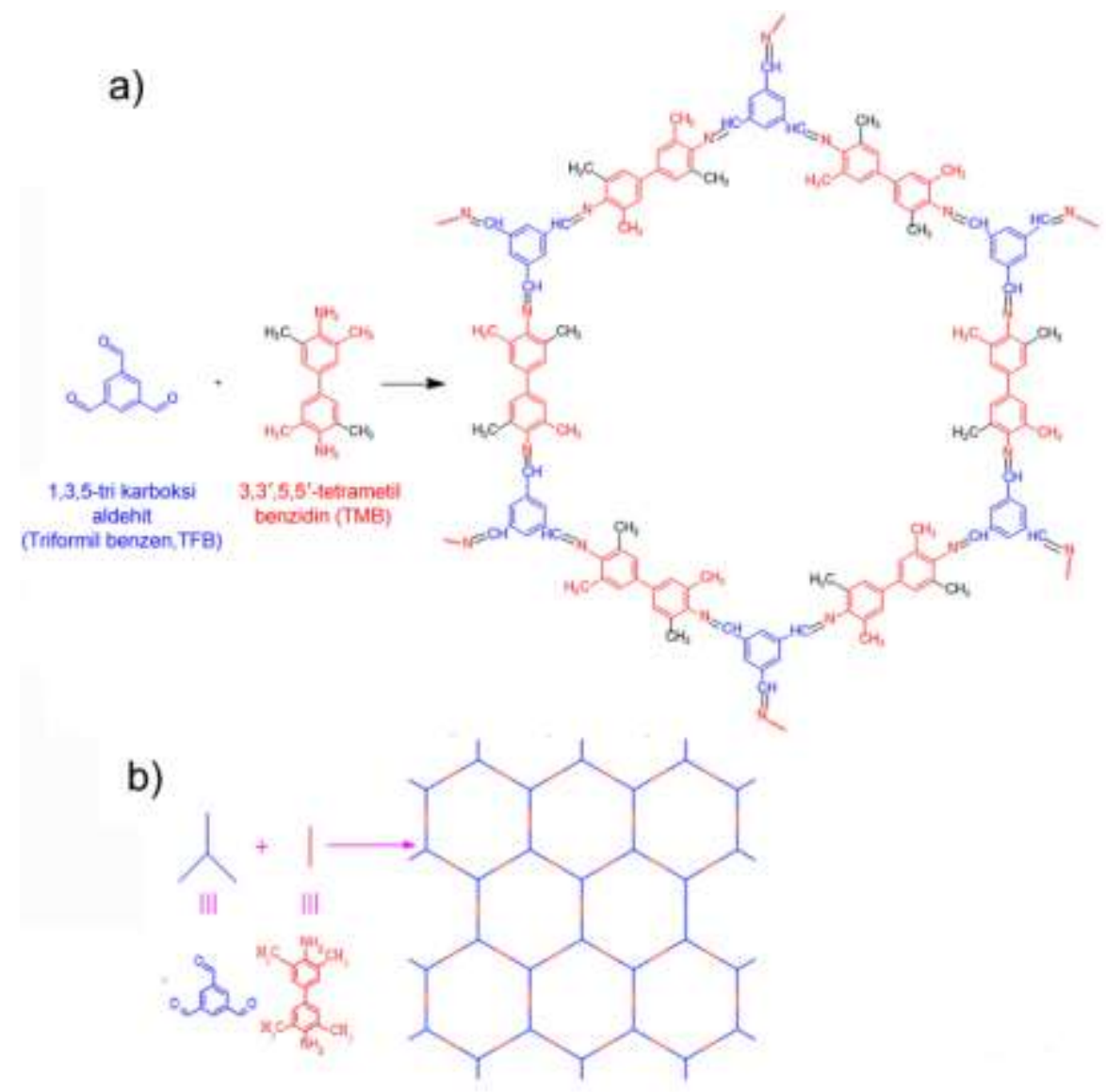

Figure 1. a) Synthesis of LA-COF-2, b) Honeycomb structure of LA-COF-2.

In addition, the stretching vibrations of $\mathrm{C}-\mathrm{N}$ single bonds are weak or moderate in the wave numbers range of approximately 1080-1360 $\mathrm{cm}^{-1}$. Accordingly, in the LA-COF-2 compound, the peaks observed at a wave number of $1131.30 \mathrm{~cm}^{-1}$ indicate the stretching vibrations of the $\mathrm{C}-\mathrm{N}$ single bond of the imine structure. When the obtained spectrum was compared to the literature, ${ }^{6,10}$ it was seen that the similar spectrum was obtained.

\subsection{PXRD analysis}

The crystallinity of LA-COF-2 was investigated by $\mathrm{Cu}$ $\mathrm{K} \alpha$ radiation with powder X-ray diffraction (PXRD) analysis. X-ray diffractogram of LA-COF-2 compound is shown in Figure $2 \mathrm{~b}$. The peak observed at $2 \theta=1.98^{\circ}$ indicates that the compound has a crystalline structure. Banarjee and co-workers ${ }^{20}$ explained that when the pores of the $\mathrm{COF}$ compounds increased in width, the sharp peak position observed at $\sim 5^{\circ}$ was observed at lower $2 \theta$ values. As seen in Figure $2 c$, the pore apertures of LA-COF- 2 were calculated as $30 \AA$. On the other hand, the wide peak observed at about $2 \theta=15^{\circ}$ can be linked to the $\pi-\pi$ interactions of the $2 \mathrm{D}$ layers shown in Figure 2d.
Similar PXRD spectra for imine-linked COF structures have been also obtained for the TpBD-COF (triformylphloroglucinol-benzidine) series by Banarjee and co-workers. ${ }^{20}$ Similarly, the results from the present study are consistent with previous studies. ${ }^{21-23}$

The previously reported three-dimensional diamond structure, the imine-bonded COF-300, is arranged with nitrogen atoms of imine bonds. Due to this arrangement, it was reported that COF-300 was reported to be able to coordinate with metal ions with less effect. Accordingly, a new imine-linked LA-COF-2 which is in two-dimensional layered-sheet structure (Figure 2d) can be an ideal choice for incorporating a variety of metal ions.

\subsection{SEM analysis}

The surface morphologies of the synthesized LA-COF-2 compound were examined using SEM analyses. Figures $3 \mathrm{a}$ and $3 \mathrm{~b}$ show the SEM images taken in various magnifications of LA-COF-2. As seen in this figures, the LA-COF-2 compound consists of particles aggregated approximately $200 \mathrm{~nm}$ in size. These particles have a layered leaf-shaped morphology. 


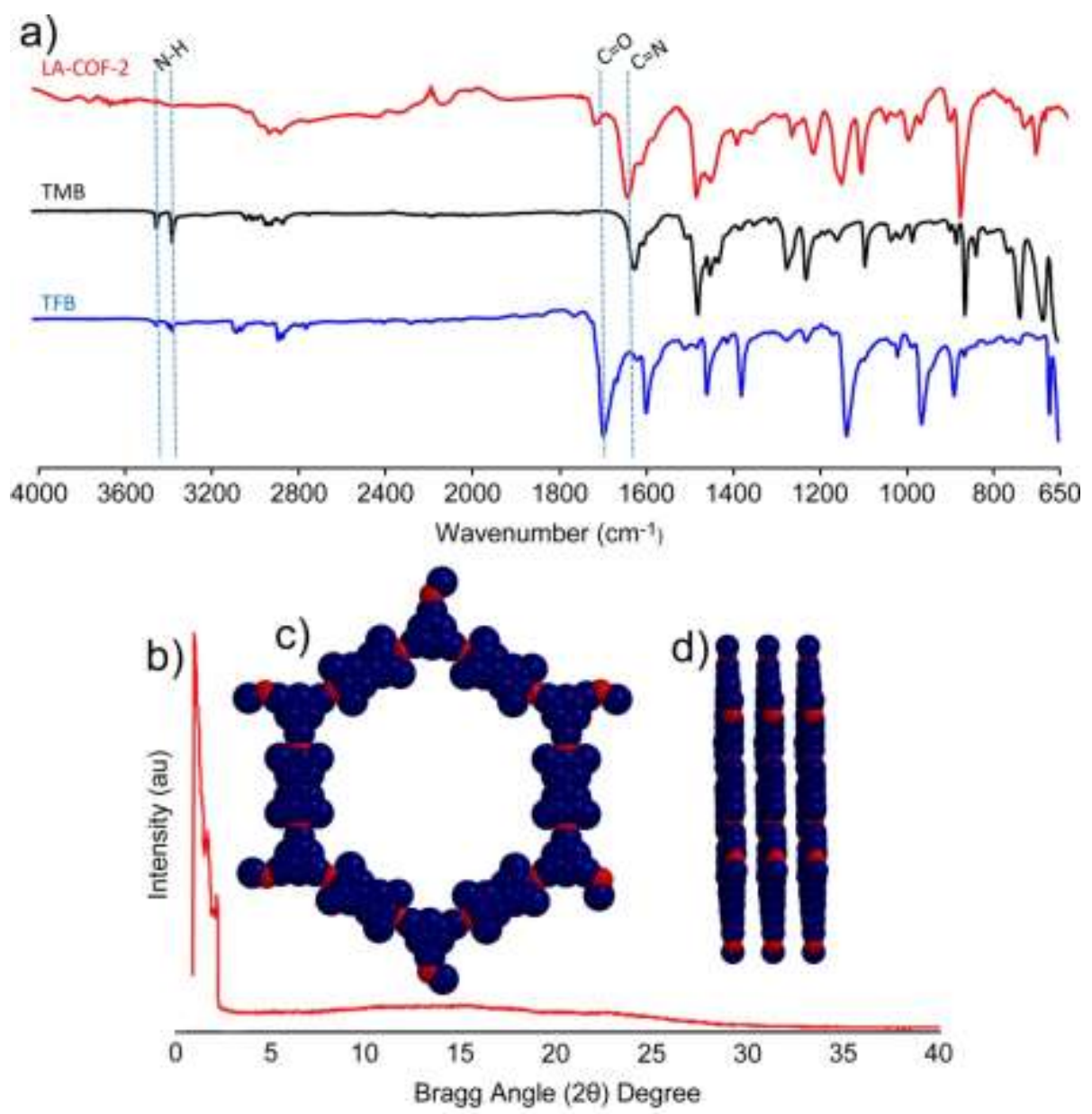

Figure 2. a) FT-IR spectra of LA-COF-2, TMB and TFB, b) X-ray diffractogram of LA-COF-2, c) 3D model of LA-COF-2, d) Side representation view of 2D-layers of LA-COF-2.

It can be thought that this structure is formed as a result of the $\pi-\pi$ interaction of hexagonal units and the layers coming together to form aggregates.

In addition, EDX mapping analysis was performed for the synthesized COF compound. Figure $3 \mathrm{c}, 3 \mathrm{~d}$ and $3 \mathrm{e}$ show the carbon, nitrogen and oxygen distribution of LA-COF-2 compound. Figure $3 f$ illustrates the EDX spectrum, which gives the percentages of the atoms in the compound by weight. The amounts of carbon, nitrogen and oxygen in LA-COF-2 have been determined as $85.44 \%, 10.05 \%$ and $4.50 \%$, respectively.

Results obtained with EDX mapping analysis are compatible with elemental analysis results. The amount of oxygen was calculated as $0.26 \%$ by elemental analysis which is a more precise analysis method. Considering the chemical structure, it can be said that the oxygen observed in the LA-COF- 2 compound is the remaining terminal oxygen of the unreacted triformyl benzene.

\subsection{TGA analysis}

Thermogravimetric analysis was used to investigate the thermal stability of LA-COF-2 and thermogram is given in Figure 4. The maximum decomposition temperature for the LA-COF-2 was determined as $446^{\circ} \mathrm{C}$. The second decomposition temperature was observed as $529^{\circ} \mathrm{C}$, and when the temperature reaches to $700^{\circ} \mathrm{C}$, it was seen that $71 \%$ of the framework structure was degraded. The thermal stability of the synthesized compound is very close to the thermal stability values of imine-linked COF compounds obtained in previous studies. $^{9,10,24}$

\subsection{Chemical stability of LA-COF-2}

In order to determine the chemical stability of LA-COF-2, $15 \mathrm{mg}$ of the samples were put into $20 \mathrm{ml}$ of water, DMA and $6 \mathrm{~N} \mathrm{NaOH}$ solution for 5 days. Samples recovered by filtration were weighed again after drying. 

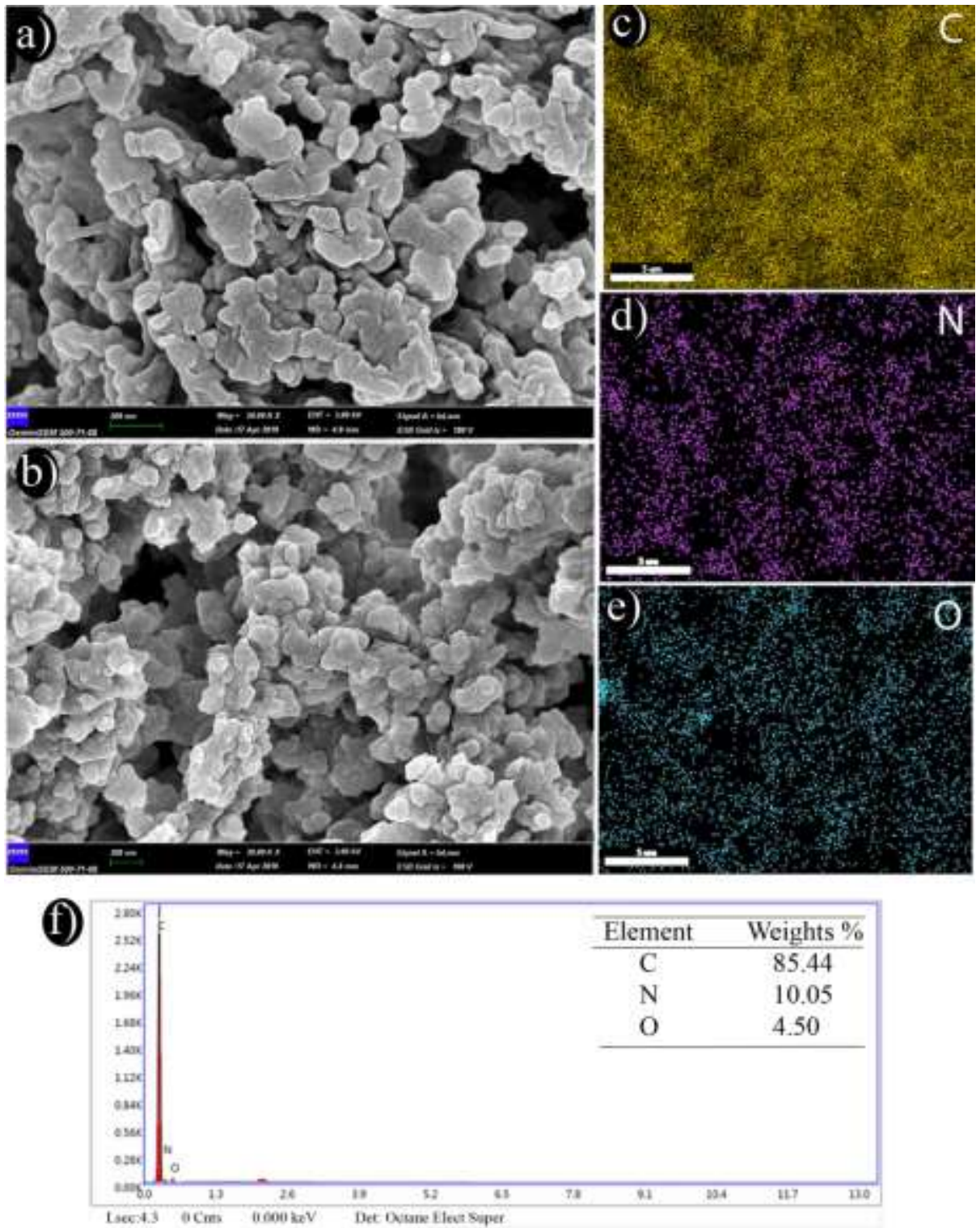

Figure 3. SEM images of LA-COF-2: a) $50 \mathrm{KX}$, b) $30 \mathrm{KX}$ magnifications. EDX mapping analysis of LA-COF-2: c) C, d) N, e) O, f) EDX spectrum of LA-COF-2 (inset table shows weight percentage of $\mathrm{C}, \mathrm{N}$ and $\mathrm{O}$ atoms).

No mass loss was observed as a result of weighing. TGA and FTIR analyses were performed on the samples treated with solvents.

DTG and TG\% thermograms for LA-COF-2 and solvent treated LA-COF-2 samples are given in Figures 5a and $5 \mathrm{~b}$, respectively. In addition, DTG max and total mass loss values of the samples are shown in a table given in Figure $5 \mathrm{~b}$. As can be seen from the table, the main decomposition temperature of about $446^{\circ} \mathrm{C}$ for LA-COF-2 compound did not change significantly when the samples were treated with the solvent. After $446^{\circ} \mathrm{C}$, all samples began to decompose at $24.4-29.4 \%$ up to $700^{\circ} \mathrm{C}$.
As understood from TGA thermogram, LA-COF-2 compound was seemed to remain stable when treated with different solvents for 5 days. FT-IR spectra of LACOF-2 compound and solvent treated LA-COF-2 samples are given in Figure $5 \mathrm{c}$. The $\mathrm{C}=\mathrm{N}$ stretching peak, which specifically indicates the imine structure in the spectrum, was recorded at approximately the same wave number after solvent treatment. However, in the sample treated with $\mathrm{NaOH}$, this peak was observed at different severity. But, no change in peak intensity was observed in the other solvents. The obtained results proved that LA-COF-2 compound has high chemical stability against base, water and organic solvent and structural integrity is maintained in the solvent. 


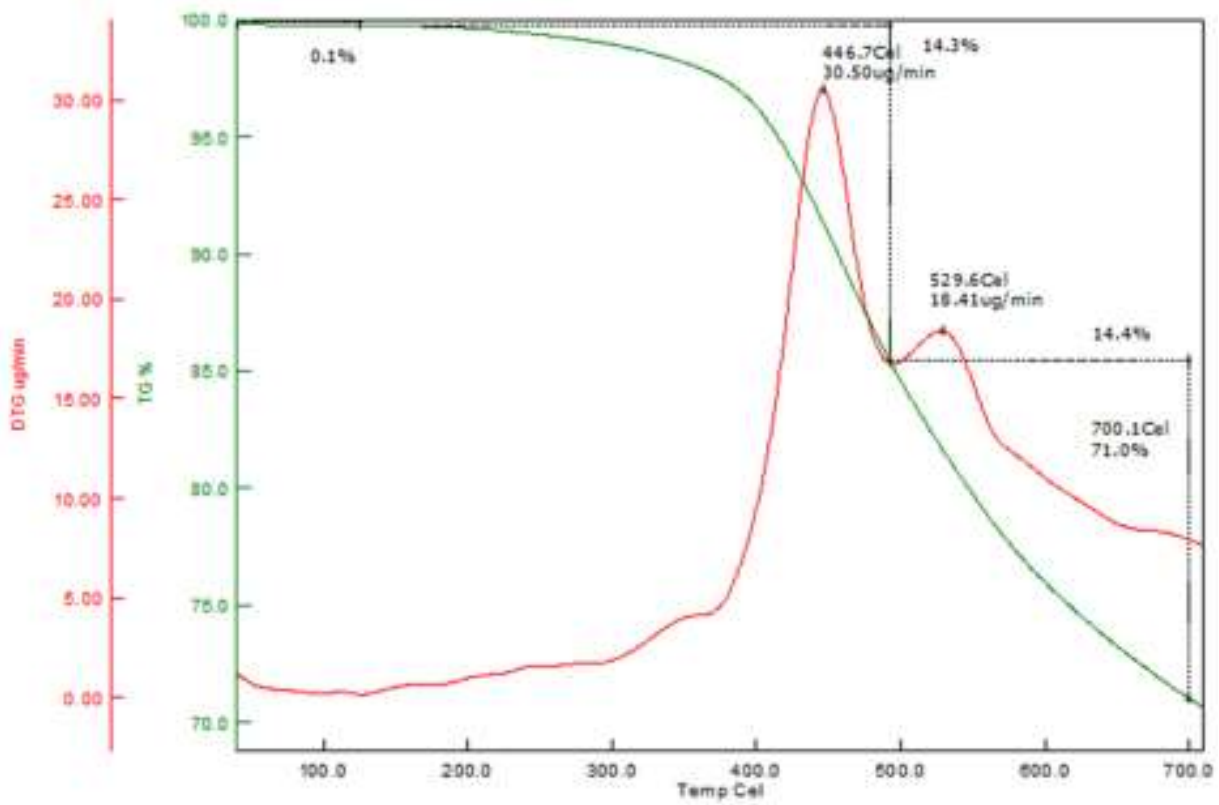

Figure 4. TGA thermogram of LA-COF-2.
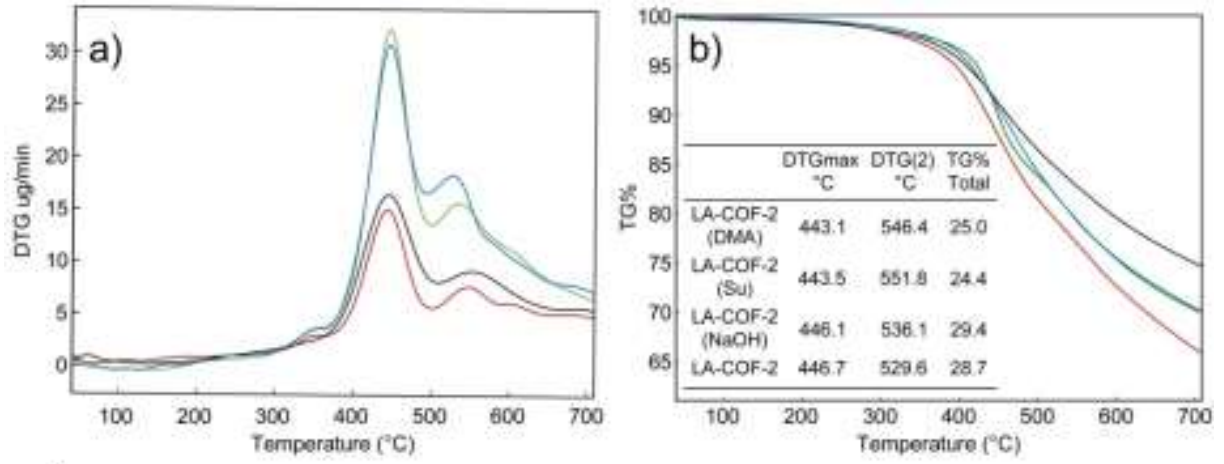

c)

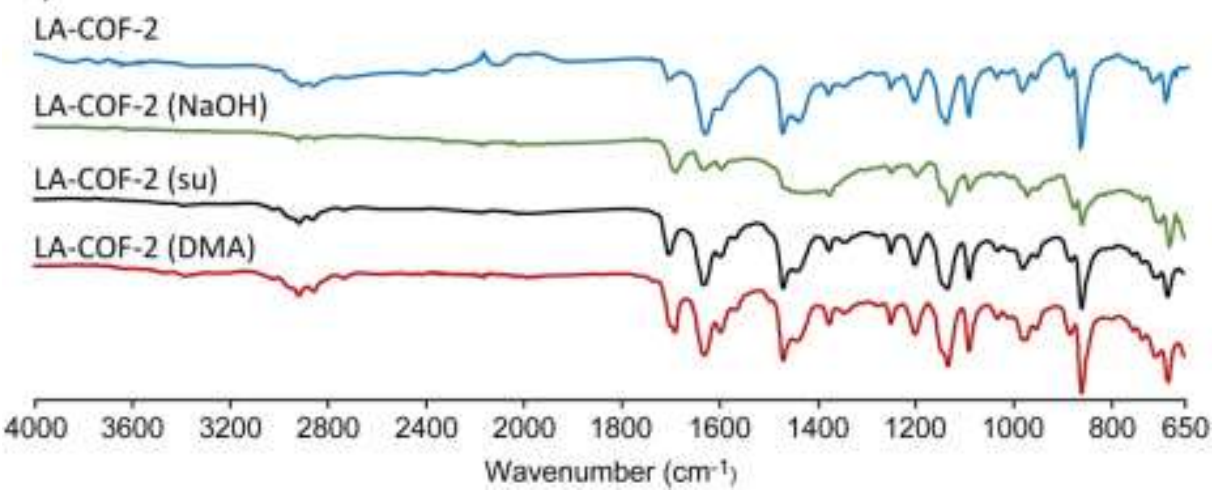

Figure 5. a) DTG curves of LA-COF-2 and solvent treated LA-COF-2, b) TG\% curves of LA-COF-2 and solvent treated LA-COF-2, c) FT-IR spectra of LA-COF-2 and solvent treated LA-COF-2. 
It has been reported in the literature, that the previously synthesized COFs are insoluble in water and common organic solvents such as hexane, tetrahydrofuran, acetonitrile, acetone, methanol and N,Ndimethylformamide. ${ }^{6,13}$ However, it has not been investigated under hard conditions such as $\mathrm{NaOH}$. Whereas, LA-COF-2 was found to be stable to $\mathrm{NaOH}$ in the present study.

\section{CONCLUSIONS}

In the present paper, a new imine-linked COF molecule with high chemical and thermal stability was successfully synthesized. The vibration peak of the imine bond $(\mathrm{C}=\mathrm{N})$ of LA-COF-2 was observed at 1626 $\mathrm{cm}^{-1}$ wave number. As a result of the images recorded by SEM analysis, it was determined that LA-COF-2 compound consisted of aggregated particles approximately $200 \mathrm{~nm}$ in size. From TGA analysis, it was determined that the synthesized compound had high thermal stability. It was observed that the synthesized LA-COF-2 compound remained stable to base, DMA and water. As a result, it was concluded that LA-COF-2 could be used in nanotechnology application areas such as drug delivery and gas storage thanks to its porous structure.

\section{ACKNOWLEDGEMENTS}

This work was supported by Aksaray University Research Fund for financial support through Project numbers BAP 2018-025.

\section{Conflict of interests}

Author declares that there is no a conflict of interest with any person, institute, company, etc.

\section{REFERENCES}

1. Cote, A. P.; Benin, A. I.; Ockwig, N. W.; O'Keeffe, M.; Matzger, A. J.; Yaghi, O. M. Science 2005, 310 (5751), 1166-1170.

2. El-Kaderi, H. M.; Hunt, J. R.; Mendoza-Cortés, J. L.; Côté, A. P.; Taylor, R. E.; O'Keeffe, M.; Yaghi, O. M. Science 2007, 316 (5822), 268-272.

3. Dogru, M.; Sonnauer, A.; Gavryushin, A.; Knochel, P.; Bein, T. Chem. Commun. 2011, 47 (6), 1707-1709.

4. Spitler, E. L.; Dichtel, W. R. Nature Chem. 2010, 2 (8), 672.

5. Tilford, R. W.; Gemmill, W. R.; zur Loye, H.-C.; Lavigne, J. J. Chem. Mater. 2006, 18 (22), 5296-5301.
6. Uribe-Romo, F. J.; Hunt, J. R.; Furukawa, H.; Klock, C.; O'Keeffe, M.; Yaghi, O. M. J. Am. Chem. Soc. 2009, 131 (13), 4570-4571.

7. Wan, S.; Guo, J.; Kim, J.; Ihee, H.; Jiang, D. Angew. Chem. Int. Edit. 2008, 47 (46), 8826-8830.

8. Wan, S.; Guo, J.; Kim, J.; Ihee, H.; Jiang, D. Angew. Chem. Int. Edit. 2009, 48 (30), 5439-5442.

9. Albacete, P.; Martinez, J. I.; Li, X.; Lopez-Moreno, A.; Mena-Hernando, S. a.; Platero-Prats, A. E.; Montoro, C.; Loh, K. P.; Perez, E. M.; Zamora, F. J. Am. Chem. Soc. 2018, 140 (40), 12922-12929.

10. Rabbani, M. G.; Sekizkardes, A. K.; Kahveci, Z.; Reich, T. E.; Ding, R.; El-Kaderi, H. M. Chem. Eur. J 2013, 19 (10), 3324-3328.

11. Akyuz, L. Micropor. Mesopor. Mat. 2020, 294, 109850.

12. Kuhn, P.; Antonietti, M.; Thomas, A. Angew. Chem. Int. Edit. 2008, 47 (18), 3450-3453.

13. Uribe-Romo, F. J.; Doonan, C. J.; Furukawa, H.; Oisaki, K.; Yaghi, O. M. J. Am. Chem. Soc. 2011, 133 (30), 11478-11481.

14. Ding, H.; Li, Y.; Hu, H.; Sun, Y.; Wang, J.; Wang, C.; Wang, C.; Zhang, G.; Wang, B.; Xu, W. Zhang, D. Chem-Eur. J. 2014, 20 (45), 14614-14618.

15. Cai, S.-L.; Zhang, Y.-B.; Pun, A. B.; He, B.; Yang, J.; Toma, F. M.; Sharp, I. D.; Yaghi, O. M.; Fan, J.; Zheng, S. R. Chem. Sci. 2014, 5 (12), 4693-4700.

16. Dogru, M.; Handloser, M.; Auras, F.; Kunz, T.; Medina, D.; Hartschuh, A.; Knochel, P.; Bein, T. Angew. Chem.- Ger Edit 2013, 125 (10), 2992-2996.

17. Zhang, W.; Qiu, L.-G.; Yuan, Y. P.; Xie, A. J.; Shen, Y. H.; Zhu, J. F. J. Hazard. Mater. 2012, 221, $147-154$

18. Ding, S.-Y.; Gao, J.; Wang, Q.; Zhang, Y.; Song, W. G.; Su, C.-Y.; Wang, W. J. Am. Chem. Soc. 2011, 133 (49), 19816-19822.

19. Ben, T.; Shi, K.; Cui, Y.; Pei, C.; Zuo, Y.; Guo, H.; Zhang, D.; Xu, J.; Deng, F.; Tian, Z. J. Mater. Chem. 2011, 21 (45), 18208-18214.

20. Karak, S.; Kandambeth, S.; Biswal, B. P.; Sasmal, H. S.; Kumar, S.; Pachfule, P.; Banerjee, R. J. Am. Chem. Soc. 2017, 139 (5), 1856-1862. 
21. Mitra, S.; Sasmal, H. S.; Kundu, T.; Kandambeth, S.; Illath, K.; Diaz Diaz, D.; Banerjee, R. J. Am. Chem. Soc. 2017, 139 (12), 4513-4520.

22. Bunck, D. N.; Dichtel, W. R. J. Am. Chem. Soc. 2013, 135 (40), 14952-14955.

23. Chandra, S.; Kandambeth, S.; Biswal, B. P.; Lukose, B.; Kunjir, S. M.; Chaudhary, M.; Babarao, R.; Heine, T.; Banerjee, R. J. Am. Chem. Soc. 2013, 135 (47), 17853-17861.

24. Wu, C.; Liu, Y.; Liu, H.; Duan, C.; Pan, Q.; Zhu, J.; Hu, F.; Ma, X.; Jiu, T.; Li, Z. J. Am. Chem. Soc. 2018, 140 (31), 10016-10024. 